(in press, Children \& Society, $6^{\text {th }}$ Feb 2015)

\title{
Informed consent with children and young people in social research: is there scope for innovation?
}

\section{Sarah Parsons ${ }^{1 *}$, Gina Sherwood ${ }^{2}$ and Chris Abbott ${ }^{3}$}

1* (for correspondence): Dr Sarah Parsons, Southampton Education School, University of Southampton, Highfield, Southampton S017 1BJ. Email: s.j.parsons@soton.ac.uk; Telephone: 02380592977

2: Dr Gina Sherwood, School of Education and Continuing Studies, University of Portsmouth, UK 3. Dr Chris Abbott, Department of Education \& Professional Studies, Kings College London, UK

\begin{abstract}
Over twenty years of research has enhanced our understanding about the methodological and ethical benefits and challenges of involving children and young people in research. Concurrently, the increasing bureaucratization of research ethics governance within UK universities has reified expectations about the methods used to gain informed consent for research participation. This paper explores how social researchers in the UK are navigating this tension and whether there is any scope for innovation through the use of technologies in how children and young people provide informed consent to take part in research. We conclude there is a need for the co-creation of research information with children and young people and greater transparency by sharing creative solutions.
\end{abstract}




\section{Introduction}

Morrow and Richards' (1996) seminal paper in this journal discussed the new sociology of childhood i.e. the societal shift towards an understanding of children as competent social actors, capable of making their own decisions and providing substantive and valid social research data. Their paper outlined some of the key issues of the impact that a changing understanding of childhood was having on the ethics of social research and provided some practical suggestions about how to negotiate the new territory. This paper is intended as a reflection on what has changed since then in the UK context and a report on the current ethics practices of social researchers, with a particular focus on informed consent for data collection. Specifically we interviewed social researchers in the UK to explore whether there is there scope for innovation in informed consent practices in research involving children and young people and, if so, what might innovation look like?

Certainly, much has changed since the publication of Morrow and Richards' (1996) paper. It was argued then that little was known about children's views and perspectives on their 'everyday lives and experiences' (p.91) because social research had not yet accessed those views, preferring instead to consider children's experiences through adult lenses (families, teachers, other professionals). As a corollary, there were few examples of researchers reflecting on the ethical processes and implications that such a child-centred research focus might entail. Subsequently, many accounts of children's lived experiences have been published, providing rich insights into their views, preferences and encounters in many different contexts (though mostly based in the UK). For example (to name only a few): disabled children and those with special educational needs talking about school, and disability (Connors \& Stalker, 2007; Cavet \& Sloper, 2004); children accessing health services (Wilson et al., 2010); young people participating in the voluntary and statutory sectors (Fleming, 2013); 'vulnerable' children receiving support services (Davies \& Wright, 2008; Aubrey \& Dahl, 2006); and children's everyday experiences of school and their roles in decision-making (Wyse, 2001; Alderson, 2000). These accounts provide 'valid sociological data' on children's lives (Morrow \& Richards, 
1996; p.98) as well as convincing evidence that children, including the very young, are competent and capable of participating in research and giving their views (Lansdown, 2011; Clark \& Moss, 2011). Researchers have also presented many reflexive accounts of their ethicsin-practice during research projects involving children and young people and other, so-called, vulnerable groups (e.g. Alderson \& Morrow, 2011; Sikes \& Piper, 2010; Farrell, 2005; Lewis et al., 2003; Christensen \& Prout, 2002; Valentine, 1999).

Methodologically and conceptually, researchers have also generated a significant body of knowledge about researching with and for children and young people, establishing some key principles. Firstly, creative, flexible, and multimodal approaches to data collection are considered essential for accessing children's views in authentic, credible and trustworthy ways (Thomas \& O’Kane, 1998; Lewis, 2002). Secondly, participatory and more inclusive research methodologies can help to ameliorate power differentials between researchers and children (e.g. Kellett et al., 2004), although of course, not completely or without ongoing challenges (Nind, 2014). Thirdly, securing and maintaining children's consent to take part in research is an essential part of an ongoing process where participation is negotiated, revisited and contextualised (Dockett \& Perry, 2011; Farrell, 2005); and fourthly, children have as much right not to participate in research; their silence or dissent should be respected in the same way as their consent and participation (Lewis, 2010; Bourke \& Loveridge, 2014). In other words, methods really matter and consent to participate in research (or not) remains a vital component of all research involving children and young people (Alderson, 2005; Peled \& Leichtentritt, 2002).

The scrutiny of such methods and procedures has also changed substantially, both in the UK and also internationally (Parsons et al., in press). Morrow and Richards (1996) noted that ethics governance and formal review of research by university research ethics committees (RECs) was something that had not yet impinged on social researchers who '...tend not to put proposals before RECs, and rely on guidelines in a fairly arbitrary manner' (p.92). This would doubtless 
meet with an ironic laugh from new researchers, or pained reminiscence by those who remember such trusting and informal times. There is an increasingly bureaucratic and formalised approach to ethics review and governance of research at universities (Wiles et al., 2005; Hammersley, 2009) where reviews by RECs has become a standard part of research governance for both externally and internally funded research in the UK university sector. However, concerns have been expressed, and examples shared, about the impact such formalisation has had on the involvement of children and young people in social research (e.g. Sikes \& Piper, 2010; Scott \& Fonseca, 2010; Crow et al., 2006). Various guidelines have also been published or updated, with general information about the need for special consideration of children in research, including guidance regarding statutory responsibilities such as safeguarding (NSPCC, 2014; ESRC, 2010; BERA, 2011). However, a recent review of the guidance from university RECs in the UK about research including children and young people (Parsons et al., in press), showed that there was very limited guidance from RECs about how researchers could ensure that legal procedures were followed in their research. Some positive aspects of the formalisation of procedures are expressed in terms of encouraging researchers to think more thoroughly from the outset about their methodology (Crow et al., 2006). However, many concerns focus on a lack of awareness from RECs about whether and how informed consent with children can be achieved, with the consequences that some research has been significantly curtailed or redesigned (Jones \& Stanley, 2008; Cuskelly, 2005).

In scrutinising the guidance provided to researchers about research including children and young people by university RECs in the UK, Parsons et al., (in press) found that although children's involvement usually elevated research to a high level of risk and review, there was very limited guidance about how to appropriately and effectively support children's consent for participation. Although, as noted above, researchers have discussed the importance of the process of consent as negotiated through projects, there are very few actual examples of how information and consent materials have been made more accessible to support children's understanding, beyond the provision of helpful general guidelines (e.g. Alderson \& Morrow, 
2004; The Research Ethics Guidebook, not dated), or brief descriptions (e.g. Thomas \& O’Kane, 1998). Specific examples are rarely, if ever, published in research articles (Peled \& Leichtentritt, 2002), although see Loyd (2012) for a more recent exception.

It is certainly surprising that the methods through which researchers gain informed consent from children, and other vulnerable groups, remain so opaque (Lewis, 2010) given what is known about the importance of creative research methods for accessing children's views, as discussed above. Moreover, Mitchell and Sloper (2002; p.74) argue that well-designed 'userfriendly' information has '...empowering potential', and Nind (2008; p.7) argues that appropriately tailored materials can 'increase capacity [to consent]'. However, Parsons et al (in press) concluded that RECs tend to assume that informed consent is a paper-based exercise, suggesting that '...research ethics practices (specifically focusing on children and young people) have become reified to a degree that potentially diminishes reflection and innovation by researchers' (see also Nind et al., 2013). Of course, the guidance that universities provide in this regard may be very different to what researchers are doing in practice. Consequently, we wanted to explore how social researchers manage this apparent tension between what the RECs say is acceptable in terms of provision of information, and what actually happens in the field.

Furthermore, given that '...real-world research...acknowledges the reality of children's everyday lives and the spaces in which they provide consent to, and engage in, the research' (Farrell, 2005; p.177), we were interested to see whether and how researchers are innovating in this area with regard to the use of technologies (Parsons \& Abbott, 2013). A critical discussion of what innovation means in research is beyond the scope of this article (see Nind et al., 2013) but we consider innovation as: 'the act or process of introducing new ideas, devices, or methods' (Merriam-Webster, 2014). Specifically, we suggest that a contemporary sociology of childhood should reflect the increasingly pervasive role of technologies in many children's everyday lives, which is changing the ways that children access, create, re-purpose and share information as well as their expectations of how and where information is presented (Rideout et al., 2010). 
This paper explores the extent to which such changes in childhood are reflected in researchers' informed consent practices and the actual or potential role of technologies in the process.

\section{Methodology}

\section{Participants and procedure}

Ten male and twenty-two female UK-based social science researchers took part; twenty-three were interviewed individually and nine took part in focus groups. The length of time interviewees had been conducting research involving children and young people ranged from four to thirty-six years and the sample included individuals who had / were currently serving on university RECs. Research encompassed babies and young people up to 18, including those with disabilities, and focused on children's involvement as research participants (rather than partners). Participants were selected from a list of names suggested by the research team based on knowledge of the field and personal contacts, supplemented by a bibliographic database search for researchers who had published relevant research in the previous five years. Each interviewee provided informed consent and interviews took place face-to-face, via Skype or over the telephone. A semi-structured interview schedule was used (Appendix 1), focusing on how consent or assent with children and young people is achieved initially and revisited during projects; and whether methods and experiences of gaining consent in the field, and ethics approval for research, have changed over time. Interviews lasted 20-76 minutes and were audio-recorded.

The focus groups took place in two different universities, making a group of four researchers in one and five in the other, and had the objective of exploring two main research questions: 'In what ways could technology make the information about research and consent more accessible to children and young people?' and 'Is there a role for capturing the decisions of children and young people to either agree or not using technology?' An agenda was circulated to participants before the focus group, outlining the topics for discussion and related activities (Appendix 2). 
Discussions were audio-recorded and lasted 1-2 hours. The research project was reviewed and approved by the University of Southampton's Faculty of Social Science ethics committee (ref \#: 5377). All participants received an information sheet and consent form via email before the interview or focus group; this information was recapitulated before discussions commenced and consent forms were signed; all participants had the opportunity to ask questions about the project.

\section{Analysis}

The qualitative analysis of the data followed a set of procedures that provided a logical chain of reasoning and iterative review (Newton Suter, 2012). Audio-files were listened to several times and detailed notes and transcripts made. Key themes and conceptual linkages were made in the second iteration, before reviewing the results of each transcript again to identify consistencies and differences in the responses between participants. The results presented below are drawn from the interviews and the focus groups.

\section{Findings}

Current methods for sharing research information with children and young people

All of the researchers described using paper-based materials to share information about research with children, which they made accessible, attractive and relevant to the target audience by using symbols (e.g. Widgit, PCS) and pictures. They agreed that conveying commonly used research terms (e.g. publish, confidentiality) in picture form is difficult and potentially misleading. Three researchers identified influential personalities in the media and linked these to the research information. One researcher described presenting information using a comic strip format incorporating speech bubbles so that young people could ask questions and the researcher could answer, which she found led to improved engagement with the content.

Seven of the participants talked about the importance of educating children about research, often likening the description to a school project. Most researchers explained the importance of 
verbal interaction and the development of trust and rapport over time alongside the provision of paper-based information. As one researcher commented, there is a need to be very careful with young children because '... [you are] coming into a set of relationships...you have to work with them.' Examples of the ways in which researchers built rapport included: the use of questions to check for understanding; combining verbal and non-verbal communication to facilitate understanding; ensuring the child decides when and where to meet the researcher if data is gathered outside of school; and allowing plenty of time for a child to make a decision about participation. The integrity of the researcher was emphasised, although many suggested that such integrity was difficult to capture on an ethics application form, yet the RECs are responsible for deciding on the '...ethical behaviour and understanding of the researcher'. A further challenge was the perceived careful management of communicating everything that the university says children should be told but in practice were not always interested in (although specific examples were not provided). Some described separating the details presented to the university from working more intuitively with the children in the field, especially regarding managing ongoing consent and dissent to participate (see below).

Six researchers described using technology to explain their research: using video clips, placing key information on social networking sites, or displaying the details on a PowerPoint presentation. Where researchers had to rely on another adult to relay project information to children, there were mixed responses, with some concerns about the level of accuracy where a teacher, support assistant, translator or parent had this responsibility. The problem of communicating enough information about the project was also exacerbated due to time and other practical constraints.

\section{Current methods for recording consent from children and young people}

Twenty described agreeing and documenting consent through the individual or their representative signing a paper-based consent form. Only three accepted verbal agreement that had sometimes been audio-recorded. Gaining informed consent was considered complex 
because it is difficult to determine the participant's level of understanding beforehand. Some interviewees felt that researchers underestimate children's comprehension of what the research entails. In order to check the accuracy of their assumptions, researchers revisited consent on more than one occasion. Seven raised concerns about the extent to which some children, including those with additional learning needs, had freedom to consent without pressure. For example, four of the participants who carried out research in schools found that the teacher approached the whole class with the expectation that all would agree to be involved in the project. Providing each participant with an envelope that they could seal in order to facilitate privacy and autonomy was suggested as one way of managing this situation.

\section{Consent or assent to participate in research}

A range of definitions and understanding of the terms 'consent' and 'assent' were shared. One researcher said that they would 'Never go along with assent because it's missing a huge opportunity ... trying to grapple with informed consent is about engaging people in the idea that research can be useful.' Another argued that assent would assume that the participant understood what they were agreeing to which they challenged as inappropriate. One participant thought that applying their interpretation of assent would mean tuning into the responses of the child in order to judge whether they wanted to continue to participate. In an effort to define the difference a researcher questioned whether '...consent [is] collaborative versus assent more individualistic?' Many acknowledged that this was a subject that had been addressed in the literature but the range of views expressed suggests there were varied interpretations of what these terms meant in practice.

Managing ongoing consent (and dissent) in research projects

Researchers discussed the creative interaction that exists during data collection and the sensitivity with which relationships are managed, which could not necessarily be communicated in ethics committee paperwork; this included children's withdrawal from the research. Fourteen participants described using non-verbal cues to determine whether participants 
wanted to continue; nine cited examples of abandoning the interview for the good of the participant. One researcher expressed concerns about the potential impact on the mental health of the child when they discussed sensitive topics, not least: '...because we as adults are upset by totally different things than children.' During data collection, and in order to support children and those with additional needs in the ongoing decision making process, one researcher suggested that wearing a T-shirt that states the researcher's role could help to remind children about ongoing research.

Researchers also communicated their ambivalence about the impact of a child withdrawing from the activity and the challenges this created in meeting their own research objectives. They identified the consequences of lack of data, frustration at not being able to find out why the child did not want to participate, and confusion over whether it was one of the activities that had made them feel uncomfortable rather than a conscious decision to abandon their participation in the research.

\section{Perceived challenges in incorporating technology into information and consent processes} Researchers in the focus groups and five of those interviewed were interested in using technology to provide research information to children and support their decision-making about participation. However, they also identified some concerns and limitations; several suggested that technology would not suit, or be welcomed by, all participants and so providing it as an option (rather than the only means of presenting information) was important. One researcher raised the point that it should never take the place of '...multi-modal human communication.' Another researcher commented that there is a '...danger is that people get too hooked on the methods - and ideas about authenticity get sidelined in finding these new methods and so it can be a little bit illusory.' This researcher felt that reliability and authenticity of consent could be undermined in the development of new methods.

The practicalities of applying technologies were identified as a further barrier; three thought that filming would be time consuming and difficult to organise and there was concern about the 
over-dependence on software designers who may have little knowledge of the individual participants. They thought that if the child became confused about the messages conveyed through the technology there would be a danger of this negatively influencing their behaviour and decision-making. Focus group discussions suggested that technologies could disrupt the normal flow of interaction. The idea of selecting a character to explain the research based on the interests of the child was viewed positively, but the problem of this becoming a misleading distraction was considered a potential barrier also. Finally, where online blogs were used it was felt important to check them regularly in case of negative content, and that if consent was given remotely there needed to be a checking system to confirm the person's identity.

\section{Opportunities for incorporating technology into information and consent processes}

The focus groups made recommendations for incorporating technology to share research information included filming children who had already experienced research participation and showing this to the next group of participants (subject to appropriate consideration of confidentiality). Participants also suggested that technology provided flexibility and facilitated the opportunity to tailor information so that individual differences could be addressed and participants could be kept updated about progress. The potential role of using a tablet computer to record the consent agreement was discussed, which participants felt could allow the child to complete questions electronically, in their own time.

When consent needed to be revisited it was suggested that technology would be useful for showing participants what had already been agreed or completed and what was coming next. Technology was also seen as supporting more opportunities for independent choice with the presentation of consent requests sent to children individually. The introduction of a videobased character who reminds the participant that they are being recorded was seen as a method to facilitate children in making an informed decision to continue to take part or withdraw. There was agreement that technology could support autonomy, providing a different way to record decisions and apply control, as shown in a project where a 'big brother' room was set up and the 
young people chose when to contribute. Although not actually used, it was suggested that relaxation monitors could measure whether the participants were comfortable to continue during the research process.

The main area in which respondents felt that technologies could offer particular affordances for information sharing and gaining consent was to promote more effective communication between the researcher and the participant so that the child's understanding of what the research involved could be improved. To manage this there were three main tools recommended: (1) social networks (2) use of video footage and (3) electronic devices (e.g. tablets, PCs, smartphones). Responses from the focus groups and four interviews showed that some researchers are already making use of social networks to communicate with participants, either to recruit children or to keep them informed of the results of the project in which they are participating (particularly valuable for longitudinal studies). Social network sites were identified as useful places where podcasts could be uploaded and viewed. It was noted that although social network online sites are very familiar to children, they are less commonly utilized by researchers, and so there could be training and awareness needs for researchers.

The opportunity to film children during data collection was considered potentially useful for developing a communication tool for children and their families. Jointly viewing video footage could enable the child and parent to discuss what the research involves, potentially enhancing the current situation where the parent is expected to read a paper copy and then explain it to the child. Electronic devices were rarely, if ever, used to convey information about a project or elicit consent but they were identified as having valuable potential for supporting these research processes. The participants agreed that most children are very familiar with, and adept at, using these devices to send messages to friends and family and so this could be a way of supporting greater interaction in the consent process. For example, children could ask questions and receive responses in a mode of communication with which they are familiar and 
comfortable and through which they might feel more private and less exposed (compared with, for example, putting their hand up in a classroom).

\section{Discussion}

Our discussions with current social science researchers in the UK, ranging from early career to the very experienced, revealed three main things: firstly, in line with previous accounts, researchers emphasized the importance of context, sensitivity and relationships for negotiating consent for research participation with children and other vulnerable groups (e.g. Crow et al., 2006; Nind, 2008). Secondly, in line with existing (though limited) guidance from UK-based university RECs (Parsons et al., in press), methods for presenting research information and consent materials largely remains a paper-based practice, albeit one augmented by discussion to varying degrees. Thirdly, there is room for innovation in informed consent practices with children and young people; researchers expressed valuable ideas (and caution) about how technologies could be used to support communication and more autonomous decision-making (cf. Parsons and Abbott, 2013).

With regard to the first point, it is not new or surprising that there was an emphasis on negotiated consent or assent and the need for sensitivity; these qualities underpin the skills and integrity that researchers take into the field when conducting engaged social research (MacFarlane, 2009; Edwards, 2002) and are well-established principles in the literature. Our findings simply reinforce their importance. With regard to the second point about specific methods used to negotiate research participation in data collection with children, we were more surprised. While there were a few researchers using more creative approaches to presenting and discussing research information, such examples were in the minority with most using paper-based information and forms with some attention to accessibility (larger font-size, simplified text, pictures and symbols). 
It is clear that while much knowledge has been disseminated about creative methods for gaining children's substantive views during a research project, this knowledge has apparently made only limited transfer into the practices of gaining consent to research participation at the beginning of, and during, projects. This could be because some researchers are not using such creative methods for gaining substantive views in their projects and so may not feel that they need to be creative in their methods for informed consent. However most, if not all, of our participants had worked with creative methods in their projects and so explanations relating to reluctance to engage with creative methods or concerns about relevance to their research are unlikely. Some researchers discussed separating what university RECs stipulate about research information and what happens in the field. This aligns with discussions in the literature that informed consent or assent practices are different from ethics-in-practice, especially in the context of longitudinal studies (MacFarlane, 2009; Renold et al., 2008). However, this means that a vital aspect of research with children - informed consent - has become divorced from the reality of social research. This is a concern, not least because many projects may not be able to accommodate the negotiation of consent over time; children may only be involved once and so there is a need to consider information provision at the start of projects with as much importance as the methods used thereafter to capture views (Parsons et al, in press).

This also raises the important issue of researchers' different conceptions and understanding about assent and consent elicited through the interviews. Views varied considerably from not considering assent as a valid concept at all through to a more pragmatic view that assent was mostly what was being aimed for at the start of research anyway by focusing on children's understanding about what they are being asked to do so that they feel comfortable and supported. Our research was not focused on drawing conceptual distinctions between consent or assent (see Dockett \& Perry, 2011 for more in-depth consideration) but, instead, sought to elicit researchers' own understanding of these terms, in the context of their ethics practices. However, our discussion about technologies, and how they may afford improved alignment between the communication of research aims and the context of children's worldviews and 
experiences, accords with the view of one of our participants who said: '...[I] never go along with assent because its missing a huge opportunity ... trying to grapple with informed consent is about engaging people in the idea that research can be useful'. In other words, our argument is that technologies could provide important scaffolding for supporting children's engagement with, and understanding of, research information such that their own decision-making is more informed and empowered (cf. Mitchell and Sloper, 2002; Nind, 2008). This is likely to be useful regardless of the actual methods used subsequently to gather substantive views within research projects.

With respect to innovation, researchers were reflective about the potential, as well as challenges, that technologies may afford in supporting children's research participation and decision-making. The kinds of technologies discussed were mainstream, rather than specialised, for example, the use of video for capturing the reality of methods and contexts, as well as explaining and revisiting project information and decisions to take part. Flewitt's (2005) research is a good example of how effective video can be; she showed parents and children film evidence as a part of the consent procedure and noted that this reassured them and enabled them to discuss the precautions that could be taken to ensure anonymity. Of course, the use of video also comes with challenges, not least about participant confidentiality and anonymity (Christensen \& Prout, 2002), but it is, nevertheless, a readily available tool that could be explored more fully in the presentation of research information.

Social networks and personal devices, such as smartphones and tablets, were discussed as potentially useful modes for sharing information and engaging participants in research. Researchers considered the potential benefits to some children including greater privacy and autonomy in decision-making; supporting two-way communication between children and researchers; and improving effective communication by allowing children to access information in their own time and space. Shuler (2012) notes that over $80 \%$ of the top selling paid Apps are targeted towards children, with 58\% targeting pre-school children. Recent headlines have also 
emphasised how competent young children are with using digital technologies, especially when compared to their parents' generation (Garside, 2014). Many children and young people are, therefore, very likely to have experience and affinity with personal technologies in a way that many adults, including researchers, do not. As Parsons and Abbott (2013; p.4) suggest: 'Through using these as a means to communicate about research, we may encourage participation through giving validation to the technology of choice of children and young people.' Although, of course, the choice of some children and young people may be to not use technology at all and some families or children may have limited access to technology (Plowman et al., 2010); consequently, researchers utilising technologies need to be aware of, and sensitive to, the potential for exclusion as well as inclusion.

However, given that there is a generational divide in the expectation and use of digital technologies in the provision of, and access to, information in everyday life it is not surprising that researchers voiced concerns about how technologies might negatively impact experiences. Such concerns include perceived threats to: multimodality, authenticity and credibility of views, the 'normal flow' of interaction, the clarity of messages conveyed, and the autonomy of researchers by having to 'rely' on software developers to disseminate information. While the ways in which any mode of communication influences engagement and participation are worthy of serious consideration, we suggest that many of the concerns raised here closely resemble those raised regarding the use of creative, child-centred methods more widely (e.g. see discussion on credibility and authenticity in Lewis, 2002). Moreover, Web 2.0 technologies focused on user-generated content via online social media and accessed via personal devices obviate the need for any specialist programming. Given that such technologies increasingly form a part of everyday interactions for many children, the idea that the technology might somehow disrupt communication or challenge authenticity and credibility of 'voices' (any more than any other means of communication) seems questionable. 
Nevertheless, there may also be an area of growing concern around the use of social networks by researchers, at a time when there is growing evidence of such environments leading to children being put at risk (Livingstone \& Brake, 2010). At the very least, researchers should not be the cause of young people entering social networking, although a more benign approach would be to make use of interactive possibilities to which young people have already signed up. In addition, the generational divide between children and their parents' use of, and expectations about, technologies raises possible tensions about the role of parents as gatekeepers in research. Parents/ carers play a critical role in determining children's involvement and in communicating to children about research (Brooks et al., 2014) and so methods used to communicate to gatekeepers also need to take their preferences and expectations into account. This is especially important when the participants are very young and / or where cultural contexts and expectations may also determine the appropriateness of methods used, including the roles played by gatekeepers (Palaiologou, 2014; Brooks et al., 2014).

This is an area where children and young people have significant expertise to contribute. The co-creation of methods and materials for supporting informed consent practices in social research with children and young people would provide fresh perspectives on an old problem (cf. Spencer et al, 2014, focusing on clinical research). However, we also agree with one of our participants who reminded us that technology is just as prone to standardisation as the traditional paper methods currently applied; consequently, it is important to remain reflexive about the methods we use. This also extends to recognising the limitations of our own study; even though participants were included to represent a range of views and experiences, both in terms of years of experience of research as well as the nature of research undertaken (e.g. age of the children involved; topic being researched), the purposive sample may not reflect the views, experiences and practices of social science researchers more widely, not least those beyond the UK. More research is needed to explore the wider relevance, nationally and internationally, as well as implications of the findings presented here. 
Finally, any initiatives require a change in thinking and many participants thought that there might be resistance to new ideas when they were presented to university RECs (cf. Nind et al., 2013). This is where we, as researchers interested in the views and experiences of children and young people, need to contribute and challenge. Returning to Morrow and Richards' (1996; p.100) wise words:

'...children have different abilities, and are encouraged to be skilled in different mediums of communication... but are nonetheless competent and confident in them, so as researchers we need to draw on these'.

Thus, while the strong commitment to supporting young people's participation has not changed in the past 20 years, the mediums of communication through which children and young people demonstrate their competence and confidence in communicating their decisions and ideas most certainly have. It is time for us to draw upon these new methods of communication if we are to continue to strive to respect children's contexts (Farrell, 2005) especially when they may differ from our own (Christensen \& Prout, 2002). 


\section{References}

Alderson, P. (2000) School students' views on school councils and daily life at school. Children \& Society, 14, 121-134.

Alderson, P. (2005) Designing ethical research with children. Chapter in A. Farrell (Ed) Ethical research with children. OUP/ McGraw-Hill: Maidenhead, pp.27-36.

Alderson, P. \& Morrow, V. (2004) Ethics, social research and consulting with children and young people. Barnardo's: Essex.

Alderson, P., \& Morrow, V. (2011). The ethics of research with children and young people: a practical handbook. SAGE Publications Ltd.

Aubrey, C., \& Dahl, S. (2006). Children's voices: The views of vulnerable children on their service providers and the relevance of services they receive. British Journal of Social Work, 36(1), 21-39.

Bourke, R. \& Loveridge, J. (2014) Exploring informed consent and dissent through children's participation in educational research. International Journal of Research \& Method in Education, 37(2), 151-165.

British Educational Research Association (BERA) (2011) Ethical guidelines for educational research. London: BERA. Available at: http://www.bera.ac.uk/researchersresources/publications/ethical-guidelines-for-educational-research-2011[last accessed $12^{\text {th }}$ August 2014].

Brooks, R., te Riele, K. \& Maguire, M. (2014) Ethics and education research. Sage Publications: London

Cavet, J., \& Sloper, P. (2004). Participation of disabled children in individual decisions about their lives and in public decisions about service development. Children \& Society, 18(4), 278-290.

Christensen, P., \& Prout, A. (2002). Working with ethical symmetry in social research with children. Childhood, 9(4), 477-497.

Clark, A., \& Moss, P. (2011). Listening to young children: The mosaic approach (Second Edition). National Children's Bureau.

Connors, C., \& Stalker, K. (2007). Children's experiences of disability: Pointers to a social model of childhood disability. Disability \& Society, 22(1), 19-33.

Crow, G., Wiles, R., Heath, S., \& Charles, V. (2006). Research ethics and data quality: The implications of informed consent. International Journal of Social Research Methodology, 9(2), 8395.

Cuskelly, M. (2005) Ethical inclusion of children with disabilities in research. Chapter in A. Farrell (Ed) Ethical research with children. OUP/ McGraw-Hill: Maidenhead, pp.97-111.

Davies, J., \& Wright, J. (2008). Children's Voices: A Review of the Literature Pertinent to LookedAfter Children's Views of Mental Health Services. Child and Adolescent Mental Health, 13(1), 2631.

Dockett, S. \& Perry, B. (2011) Researching with Young Children: Seeking Assent. Child Indicators Research, 4(2), 231-247. 
Edwards, A. (2002). Responsible Research: ways of being a researcher. British Educational Research Journal, 28(2), 157-168.

ESRC (2010) Framework for research ethics (FRE) (updated September 2012). Online at: http://www.esrc.ac.uk/about-esrc/information/research-ethics.aspx [last accessed 12th August 2014]

Farrell, A. (2005) (Ed) Ethical research with children. OUP/ McGraw-Hill: Maidenhead.

Fleming, J. (2013). Young People's Participation-Where Next?. Children \& Society, 27(6), 484495.

Flewitt, R. (2005). Conducting research with young children: Some ethical considerations. Early Child Development and Care, 175(6), 553-565.

Garside, J. (2014) Ofcom: six-year-olds understand digital technology better than adults. The Guardian, $7^{\text {th }}$ August 2014. http://www.theguardian.com/technology/2014/aug/07/ofcomchildren-digital-technology-better-than-adults [accessed 11th August 2014]

Hammersley, M. (2009) Against the ethicists: on the evils of ethical regulation. International Journal of Social Research Methodology, 12(3), 211-225.

Jones, M., \& Stanley, G. (2008). Children's lost voices: ethical issues in relation to undertaking collaborative, practice-based projects involving schools and the wider community. Educational Action Research, 16(1), 31-41.

Kellett, M., Forrest (aged ten), R., Dent (aged ten), N. and Ward (aged ten), S. (2004), 'Just teach us the skills please, we'll do the rest': empowering ten-year-olds as active researchers. Children \& Society, 18: 329-343.

Lansdown, G. (2011) Every Child's Right to be Heard. London: Save the Children/ UNICEF. Available online from www.savethechildren.org.uk

Lewis, A. (2002) Accessing, through research interviews, the views of children with difficulties in learning. Support for Learning, 17(3), 110-116.

Lewis, A. (2010) Silence in the context of 'child voice'. Children \& Society, 24(1), 14-23.

Lewis, V., Kellett, M., Robinson, C., Fraser, S., \& Ding, S. (Eds.). (2003). The reality of research with children and young people. Sage.

Livingstone, S., \& Brake, D. R. (2010). On the rapid rise of social networking sites: New findings and policy implications. Children \& Society, 24(1), 75-83.

Loyd, D. (2013). Obtaining consent from young people with autism to participate in research. British Journal of Learning Disabilities, 41(2), 133-140.

Macfarlane, B. (2009) Researching with integrity: the ethics of academic enquiry. Abingdon, Oxon: Routledge.

Merriam-Webster (2014) Innovation (definition). http://www.merriam-webster.com/dictionary/innovation [last accessed 19th December 2014] 
Mitchell, W. \& Sloper, P. (2002) Information that informs rather than alienates families with disabled children: developing a model of good practice. Health and Social Care in the Community, $10(2), 74-81$.

Morrow, V., \& Richards, M. (1996). The ethics of social research with children: An overview. Children \& society, 10(2), 90-105.

Newton Suter, W. (2012) Introduction to Educational Research: A Critical Thinking Approach Second Edition, London, Sage.

Nind, M. (2008) Conducting qualitative research with people with learning, communication and other disabilities: methodological challenges. National Centre for Research Methods, 24pp. (ESRC National Centre for Research Methods Review Paper, (NCRM/012)).

Nind, M. 2014. What is Inclusive Research? London: Bloomsbury Academic.

Nind, M., Wiles, R., Bengry-Howell, A. \& Crow, G. (2013) Methodological innovation and research ethics: forces in tension or forces in harmony? Qualitative Research, 13(6), 650-667.

NSPCC (2014) Gillick competency and Fraser guidelines. Available at: http://www.nspcc.org.uk/Inform/research/briefings/gillick wda101615.html [last accessed 19th December 2014].

Palaiologou, I. (2014). 'Do we hear what children want to say?' Ethical praxis when choosing research tools with children under five. Early Child Development and Care, 184(5), 689-705.

Parsons, S. \& Abbott, C. (2013) Digital technologies for supporting the informed consent of children and young people in research: the potential for transforming current research ethics practice. EPSRC Observatory for Responsible Innovation in ICT

Parsons, S. Abbott, C., McKnight, L. \& Davies, C. (in press). High risk yet invisible: conflicting narratives on social research involving children and young people, and the role of Research Ethics Committees. British Educational Research Journal.

Peled, E., \& Leichtentritt, R. (2002). The ethics of qualitative social work research. Qualitative Social Work, 1(2), 145-169.

Plowman, L., McPake, J., \& Stephen, C. (2010). The technologisation of childhood? Young children and technology in the home. Children \& Society, 24(1), 63-74.

Renold, E., Holland, S., Ross, N. J., \& Hillman, A. (2008). 'Becoming Participant' - Problematizing 'Informed Consent' in Participatory Research with Young People in Care. Qualitative Social Work, 7(4), 427-447.

Research Ethics Guidebook (not dated) http://www.ethicsguidebook.ac.uk/ [accessed $11^{\text {th }}$ August 2014]

Rideout, M.A., Foehr, U.G. \& Roberts, D.F. (2010) Generation M2: media in the lives of 8-to-18year-olds. A Kaiser Family Foundation Study. Available at:

http://kff.org/other/report/generation-m2-media-in-the-lives-of-8-to-18-year-olds/ [last accessed 28 th July 2014]

Scott, C. L., \& Fonseca, L. (2010). Overstepping the mark: Ethics procedures, risky research and education researchers. International Journal of Research \& Method in Education, 33(3), 287-300. 
Shuler, C. (2012). iLearn II; An Analysis of the Education Category of the iTunes App Store. New York: The Joan Ganz Cooney Center.

Sikes, P., \& Piper, H. (2010). Ethical research, academic freedom and the role of ethics committees and review procedures in educational research. International Journal of Research \& Method in Education, 33(3), 205-213.

Spencer, G., Boddy, J. \& Rees, R. (2014) "What we think about what adults think": Children and young people's perspectives on ethics review of clinical research with children. http://nuffieldbioethics.org/wpcontent/uploads/Report_young_peoples_perspectives_on_ethics_review2.pdf [last accessed 19th December 2014].

Thomas, N., \& O'Kane, C. (1998). The ethics of participatory research with children. Children \& Society, 12(5), 336-348.

Valentine, G. (1999). Being seen and heard? The ethical complexities of working with children and young people at home and at school. Ethics, place and environment, 2(2), 141-155.

Wiles, R., Heath, S., Crow. G. \& Charles, V. (2005) Informed Consent in Social Research: A Literature Review. ESRC National Centre for Research Methods. NCRM Methods Paper Series.

Wilson, M. E., Megel, M. E., Enenbach, L., \& Carlson, K. L. (2010). The voices of children: stories about hospitalization. Journal of Pediatric Health Care, 24(2), 95-102.

Wyse, D. (2001) Felt tip pens and school councils: children's participation rights in four English schools. Children \& Society, 15, 209-218. 


\section{Appendix 1: Semi-structured interview schedule for social science researchers}

1. Can you describe how long you been working in research and the types of projects undertaken with children and young people (CYP) and other 'vulnerable' participants?

2. How do you explain research to CYP (and other 'vulnerable' participants)?

3. What ways have you used to gain informed consent from these participants?

- Probe: how have you handled incidences of dissent / withdrawal?

- Probe: what are your thoughts on whether there is a difference between consent and assent to participate in research by CYP?

Do you revisit consent during the course of a project and, if so, what prompts this?

4. Can you share examples of information sheets and consent forms that you have adapted for use with CYP and others? Talk me through your decision making as you were developing these materials.

5. Have you ever considered or used different modes of communication or presentation to assist with the informed consent process? If so, for whom and how did you do this?

6. Reflecting on research that you have been involved in, is there anything you would do differently regarding how you gained informed consent from participants?

7. Over time what, if anything, has changed or developed about the methods and processes you use to gain informed consent in your research?

8. How would you characterise your experience of seeking ethical review and approval from institutional research ethics committees for research projects involving CYP (and others)?

- Probe: Has this changed over time?

○ Probe: Was it a 'high risk' or 'low risk' project (and who decided this)? 


\section{Appendix 2: Excerpt from focus group agenda outlining the discussion topics and related activities}

\section{Key questions are:}

- How do we know that someone understands the information that has been provided?

- How do we know that someone is participating voluntarily?

- How can we provide a suitable audit trail to show that someone is happy to take part?

Activity 1: In pairs, take a look at the example information sheet and consent form - what are the key pieces of information? What do you think about the way this has been done? Are there ways that these pieces of information could be presented or engaged with using technology? Which technologies could be useful for this? Share ideas and suggestions.

Activity 2: Thinking now about three key areas of informed consent [at all times keeping information and responses secure]:

○ how to explain the research to potential participants and gatekeepers (e.g. teachers, parents / guardians);

○ how to gain evidence of decision-making including signatures (or alternatives);

$\circ$ how to revisit and check on-going consent throughout a project.

In 2 or 3 groups: pick ONE of these aspects and come up with some creative solutions using technology to illustrate how you could approach this for the example project provided. 